\title{
PERSPECTIVA PEDAGÓgICA DEL PROFESORADO DE EDUCACIÓN PRIMARIA SOBRE LAS \\ MISIONES HUMANITARIAS Y DE PAZ EN LA ESCUELA
}

\section{Juan J. Leiva Olivencia}

\section{RESUMEN}

¿Es posible una educación para la paz en la escuela a partir del análisis de la imagen de las misiones humanitarias y de paz de las Fuerzas Armadas Españolas? Este es el punto de partida de un artículo que pretende exponer algunos de los resultados más relevantes sobre esta cuestión escasamente estudiada en el ámbito pedagógico. Los datos ponen de manifiesto que en el profesorado existe una visión negativa acerca de la imagen de las misiones humanitarias y de paz, y que resulta complejo su aprovechamiento educativo en las aulas.

Palabras clave: educación para la paz, misiones humanitarias, fuerzas armadas; educación en valores.

\section{TITLE: PEDAGOGICAL PERSPECTIVE OF PRIMARY SCHOOL TEACHERS ON HUMANI- TARIAN AND PEACE MISSIONS IN SCHOOLS}

\section{ABSTRACT}

Is it possible to have a peace education in school from the analysis of the image of humanitarian and peace missions of the Spanish armed forces? This is the starting point of an article that aims to expose some of the most relevant results on this issue barely studied in the educational field. Data show that there is a negative view about the image of humanitarian and peace missions among teachers, and highlighting their educational use in the classroom has become a complex task.

Keywords: education for peace, humanitarian missions, armed forces, education in values.

Correspondencia con el autor: Juan J. Leiva Olivencia. < juanleiva@uma.es >. Departamento de Didáctica y Organización Escolar. Universidad de Málaga. Original recibido: 25-01-I4. Original aceptado: 03-06-14 


\section{Introducción}

Desde sus inicios, los numerosos estudios realizados sobre la educación para la paz, la intensa difusión de distintos manuales y materiales didácticos, así como los propios y diferentes posicionamientos que al respecto se han generado, constituyen una clara muestra de la responsabilidad otorgada a la escuela en la formación cívica de los más jóvenes (Galtun, 2003; Jares, 1999; Muñoz y Molina, 2009; Ospina, 2010; Tuvilla, 1998 y 2004), pero también ponen de manifiesto la escasa consideración y vinculación entre educación para la paz y las misiones humanitarias y de paz desarrolladas por las Fuerzas Armadas. Esta situación no es común en los países de la Unión Europea, pero sí en España (Díez, 1999; García, 2008). Este es el punto de partida del presente artículo que pretende exponer los resultados de un estudio de investigación desarrollado en centros educativos de Educación Infantil y Primaria de la provincia de Málaga durante el curso 201 I/2012.

\section{La imagen social de las misiones humanitarias y de paz en el ámbito pedagógico}

La legitimación social es un componente indispensable de la actuación de las Fuerzas Armadas en general y de las intervenciones de paz en particular. Para Dandeker y Gow (1997), la legitimidad de una intervención no consiste en su legalidad ni tampoco en la existencia de consentimiento tácito por parte de la sociedad. De hecho, tal y como plantea Ajangiz (2003), para que una intervención sea legítima deben cumplirse tres condiciones: que existan principios y valores normativos que avalen esa intervención; que exista apoyo social y de los grupos políticos; y que se obtengan los resultados apetecidos, es decir, que sea eficaz y competente. Además, tal y como plantea Ajangiz (2003, p. 37), es posible que el "intento de reconvertir a los ejércitos en una fuerza humanitaria y de paz se ha visto frustrado, al margen de sus limitaciones estructurales, por unos gobiernos que no han demostrado la convicción necesaria: la imagen de las fuerzas armadas nacionales y de su papel en esas misiones ha desplazado a un segundo plano el compromiso por cumplir los objetivos básicos del mandato internacional”.

Desde el punto de vista del estado de la cuestión en el contexto español, son escasas las referencias y evidencias empíricas en materia de vincular educación para la paz y la imagen social existente en la escuela en relación a las Fuerzas Armadas Españolas. Sí existen trabajos relevantes desarrollados con jóvenes universitarios (Martín y Olianas, 2006). En este caso, en un estudio titulado "La juventud universitaria española 
ante la defensa nacional: encuesta sobre su percepción y actitudes", desarrollado por la Asociación de Diplomados en Altos Estudios de la Defensa Nacional (ADALEDE), uno de los pocos y mejores grupos de investigación españoles dedicados al estudio y promoción de la educación para la paz vinculándolo al desarrollo de las iniciativas de paz de las Fuerzas Armadas Española. Con una muestra de $30 \mathrm{I}$ jóvenes universitarios con una edad media de 21 , hallaron resultados sumamente esclarecedores. Los resultados obtenidos revelaron que la incorporación de los jóvenes a las Fuerzas Armadas no parece interesar demasiado a los jóvenes: entre un cuarto y un tercio de los encuestados lo consideran poco útil y se manifiestan indiferentes hacia la misma. Sólo una minoría de los jóvenes encuestados muestran algún interés por el tema de la incorporación a los ejércitos (un tercio por lo que se refiere a la milicia profesional y menos de una cuarta parte respecto a los militares de reserva); y de ellos, sólo un $8 \%$ manifiesta poco interés hacia todo lo militar. Y, en cuanto a las operaciones internacionales de paz en el extranjero (Golfo, ex Yugoslavia, Irak, Afganistán, etc.), la mitad de los encuestados, y más aún por las mujeres, las consideran operaciones importantes, pero poco reconocidas, ya que no se les da la publicidad que merecen. Pero hay también algunos que consideran que las acciones humanitarias son sólo un término utilizado para maquillar "acciones militares que albergan intereses políticos y económicos” (Ibíd., 2006, p. 12).

En las sociedades democráticas de nuestro entorno europeo, los ejércitos no constituyen un poder autónomo, no tienen una dinámica propia, sino que están sometidos al poder civil legítimamente establecido (Rodríguez, 20I0). Con el fin de poder asumir los valores asociados a una concepción democrática de la organización social y política, Rodríguez (2010) considera que los alumnos han de conocer, en líneas generales, cuáles son las misiones que la sociedad puede encomendar a las Fuerzas Armadas, la organización sobre la que se sustentan y el esfuerzo que es necesario realizar para mantener esta estructura con capacidad para actuar en escenarios a menudo muy alejados.

Por su parte, desde el punto de vista de la normativa educativa, resulta conveniente subrayar que la presencia y potencialidad pedagógica de las misiones de paz y humanitarias protagonizadas por las Fuerzas Armadas pueden incluirse en el marco curricular de Educación para la Ciudadanía y Derechos Humanos, área curricular del tercer ciclo de la Educación Primaria y que, en la mayoría de las comunidades autónomas, se imparte en $5^{\circ}$ curso (Casas, De la Esperanza y Martín-Pinillos, 2007). Así, en el Real Decreto 15 I3/2006, de 7 de diciembre (BOE de 8 de diciembre de 2006), por el que se establecen las enseñanzas mínimas de la 
Educación Primaria. En concreto, en relación a la competencia social y ciudadana se establece que esta competencia "supone comprender la realidad social en que se vive, afrontar la convivencia y los conflictos empleando el juicio ético basado en los valores y prácticas democráticas, y ejercer la ciudadanía, actuando con criterio propio, contribuyendo a la construcción de la paz y la democracia, y manteniendo una actitud constructiva, solidaria y responsable ante el cumplimiento de los derechos y obligaciones cívicas". Y como bloque de contenido donde se pueden trabajar estos temas de educación para la paz y seguridad humana nos encontramos con el denominado bloque 3 "Vivir en sociedad", donde se plantea la necesidad de que los niños y niñas estudien que "algunos de los servicios públicos y de los bienes comunes reciben un tratamiento específico adecuado a la edad de este alumnado, es el caso de la protección civil, la seguridad, la defensa al servicio de la paz y la educación vial”. En efecto, se incluyen como contenidos la seguridad integral del ciudadano, así como la valoración de la defensa como un compromiso cívico y solidario al servicio de la paz.

\section{Las misiones humanitarias y de paz en la escuela desde la perspectiva docente: un estudio de investigación}

Vamos a exponer a continuación las principales conclusiones del estudio de investigación desarrollado en la provincia de Málaga y titulado "Concepciones docentes y percepciones del alumnado de educación primaria sobre educación para la paz y las fuerzas armadas españolas: un estudio de caso", referidos fundamentalmente a las concepciones pedagógicas de los profesores sobre el objeto de estudio. En este punto, pretendíamos conocer y comprender las concepciones y percepciones de los docentes de Educación Primaria sobre la Educación para la Paz y su vinculación con el papel de las Fuerzas Armadas en una sociedad democrática como es la española.

\section{I. Objetivos}

El objetivo principal de esta investigación ha sido conocer las concepciones docentes así como las percepciones que tiene el alumnado de Educación Primaria sobre la Educación para la Paz y su vinculación con la Fuerzas Armadas Españolas. De manera más específica, pretendíamos, por un lado, conocer las concepciones que tienen los docentes de educación primaria sobre el papel de las Fuerzas Armadas Españolas y su vinculación con el desarrollo de la Educación para la Paz; y otro lado, analizar la imagen social de las Fuerzas Armadas Españolas en el contexto escolar de 
educación primaria, reconociendo potencialidades y debilidades en la construcción de la Educación para la Paz y el papel de las Fuerzas Armadas Españolas en el ámbito de las competencias de seguridad y promoción de la paz.

\subsection{Metodología}

Para el desarrollo del citado estudio, empleamos un cuestionario y entrevistas semiestructuradas. Se diseñó un cuestionario de elaboración propia con 43 ítems, estructurado en tres grandes bloques de contenido. En concreto, 5 preguntas de datos generales y descripción de la muestra, 23 preguntas sobre educación para la paz y su aplicación didáctica, y 15 cuestiones sobre la imagen social de las Fuerzas Armadas en la escuela, su contribución a la educación para la paz y posibilidades de integración en el curriculum y en la vida escolar de los centros educativos de primaria. Así, para la parte cuantitativa determinamos el tamaño de la muestra que resultó de 80 docentes, establecimos un nivel de confianza del $95 \%$, se estimó un margen de error del $\pm 4 \%$. No se realizó un sistema de muestreo probabilístico y estratificado al ser una población total bien delimitada: profesorado de centros educativos de infantil y primaria, tanto públicos como privados de la provincia de Málaga. Finalmente, el profesorado participante ascendió a 56 profesores los cuales pertenecían a cuatro centros educativos de tres municipios de la provincia. También realizamos 23 entrevistas semiestructuradas a docentes de centros educativos que desarrollan proyectos educativos de educación para la paz y mejora de la convivencia escolar, siguiendo las indicaciones del Decreto 19/2007, de 23 de enero, por el que se adoptan medidas para la promoción de la Cultura de Paz y la Mejora de la Convivencia en los Centros Educativos sostenidos con fondos públicos, así como la Orden de II de abril de 20I I, por la que se regula participación de los centros docentes en la Red Andaluza "Escuela: Espacio de Paz" y el procedimiento para solicitar reconocimiento como Centros Promotores de Convivencia Positiva (Convivencia+), y la Orden de 20 de junio de $20 \mathrm{II}$, por la que se adoptan medidas para la promoción de la convivencia en los centros docentes sostenidos con fondos públicos.

A continuación vamos a exponer los resultados cualitativos y cuantitativos más destacables y relevantes en el análisis de contenido temático realizado a las entrevistas. En ambos casos empleamos un análisis categorial en base a una codificación temática tal y como plantean Stake (1998) y Ruiz (1996). En este sentido, debemos mencionar que fueron cuatro las categorías temáticas que sobresalieron del análisis de contenido tanto de la parte estadística como de las entrevistas realizadas: la concepción 
pedagógica sobre la educación para la paz, la práctica de la educación para la paz, la imagen social de las Fuerzas Armadas entre el profesorado de Educación Primaria $y$, finalmente, la potencialidad y valor pedagógico de las misiones humanitarias y de paz de las Fuerzas Armadas.

\subsection{Resultados}

La conclusión más relevante que se desprende de nuestro estudio es que la mayoría de docentes no tiene una visión positiva de las Fuerzas Armadas en relación al objeto de nuestro estudio. Es decir, la mayoría de los profesores entrevistados considera que la imagen social de las Fuerzas Armadas es negativa por diferentes factores históricos e ideológicos, a pesar de reconocer la importancia de sus funciones constitucionales y también las misiones humanitarias que desarrollan en muchos países del mundo. Ciertamente, nos encontramos con docentes que distinguen bien entre misiones humanitarias y misiones de paz, y es que la mayoría está de acuerdo con el papel que realizan las Fuerzas Armadas en las misiones humanitarias pero se cuestionan su papel en las misiones de paz. ¿A qué se debe esta diferenciación que realizan estos docentes? Posiblemente a que la imagen social que tienen las Fuerzas Armadas está mediatizada no tanto por el éxito y profesionalidad de estas misiones sino por la política de comunicación de los gobiernos de turno, y por tanto, la crítica de los docentes es mayor a los políticos gestores de las Fuerzas Armadas que a la propia institución militar. Ahora bien, la mayoría considera que vincular educación para la paz y Fuerzas Armadas es algo chocante, incongruente e incoherente. Las palabras de esta docente son contundentes en relación a lo explicado:

E: Bueno, entrando en materia sobre el proyecto que estamos realizando desde la UMA. Sabes que las Fuerzas Armadas Españolas (FAES) desarrollan misiones humanitarias y de paz fuera de nuestro país, ino? Entonces me gustaría preguntarte sobre si es posible, para ti, desde tu perspectiva como docente, trabajar estas misiones y esta imagen pacífica de las FAES en el marco de la educación para la paz que estáis desarrollando en tu centro educativo...o lo ves difíil, o cómo lo ves...

P: Ummm. Yo personalmente, ya no solo como docente, sino como persona, lo veo un poco incongruente...Es una imagen que a lo mejor no se puede traslucir de todo esto...que unas fuerzas armadas, que el mismo nombre dice que están armadas parece que lo lógico no es que sean de paz, no sé, no son fuerzas del orden, no sé, que el nombre parece menos agresivo, ino? Llevarlo al tema educativo, al tema de la paz, para mí resulta bastante chocante en mi opinión...Que sí es verdad que se realizan muchísimas tareas humanitarias y todo donde intervienen es humanitaria.... 
Esta mirada docente es compartida por la mayoría de los docentes entrevistados, es decir, que para estos profesores de Educación Primaria el vincular el papel de las Fuerzas Armadas con la educación para la paz, incluso empleando las misiones humanitarias y de paz, puede resultar ilógico aunque reconocen el papel cada vez más relevante de las Fuerzas Armadas Españolas en el mundo. Sin embargo, los docentes son muy críticos en el sentido de cuestionar el carácter de las misiones que realizan las Fuerzas Armadas en el exterior, y es que como plantea una docente "lo que pasa es que muchas veces se venden como misiones humanitarias pero a lo mejor no son realmente humanitarias, y eso es muy importante. No se puede vender cosas humanitarias cuando no lo son tanto. Por ejemplo, el caso concreto de Afganistán, estamos viendo que es una misión humanitaria, que realmente están defendiéndose, que están atacando, siendo bombardeados". Esta consideración negativa no es atribuible a las Fuerzas Armadas, sino a la política de gestión y de comunicación que los responsables políticos realizan en determinadas misiones que no están bien vistas por la población española. En este sentido, los docentes son muy sensibles a la consideración y concepción de paz cuando los medios de comunicación ofrecen una imagen bien distinta de los países donde realizan tareas de paz o, mejor dicho, de pacificación. Esto también es un matiz importante y es que los docentes no están de acuerdo con las misiones de pacificación pero sí con las de paz. ¿Cuál es la diferencia? Que en las misiones de paz se presupone que la acción militar va más encaminada a mejorar la situación de seguridad humana de la población del país donde se actúa mientras que las misiones de pacificación tienen un significado más territorial y circunscrito al mantenimiento de un determinado poder contra grupos o unidades militares o terroristas. Lógicamente, los docentes consideran que nuestras Fuerzas Armadas van a defender los valores de la paz, la democracia y la libertad, pero se cuestionan si existen o no intereses ocultos o implícitos en el propio mandato o configuración de la misión. Así lo expresa una profesora:

E: Sí, que crees que la culpa o responsabilidad, llamémoslo así, tiene que ver con esa manera de vender las misiones humanitarias...

P: Sí, pero no es tanto las FAES. Para mí la culpa de esta situación es de los políticos, porque son los políticos los que denominan con un nombre más eufemístico, menos agresivo socialmente, pero que realmente algunas misiones llamadas de paz son misiones de guerra...No, es que vamos en misión de paz, cuando luego realmente no es cierto. Por tanto, si no nos engañaran los políticos yo pienso que la imagen de las FAES, y sobre todo, en el caso concreto de las misiones de paz, pues se valorarían mucho más por parte de toda la población... 
En la mayoría de las entrevistas realizadas surgen varias misiones desarrolladas o en desarrollo por parte de las Fuerzas Armadas Españolas, como es Afganistán, Líbano o Bosnia. En este punto, los docentes son muy críticos con la actuación militar en Afganistán, lo cual nos puede hacer recordar lo que ocurrió hace ya años en Irak, pero se muestran muy orgullosos de la intervención militar española en países como Bosnia o incluso Haití. Es más, consideran que la imagen social de las Fuerzas Armadas sería más positiva para toda la sociedad española si el tipo de misiones internacionales fueran más humanitarias y de paz como el caso de Bosnia, mientras que tiene muy mala fama y es muy criticado por los docentes el papel de las Fuerzas Armadas en Afganistán. Lógicamente, todos comparten la idea de que las Fuerzas Armadas son una institución que está al servicio del poder constitucional y democrático, y, por tanto, que las críticas no van tan dirigidas a las Fuerzas Armadas sino a los dirigentes y políticos que orientan y dictan las misiones, los objetivos y el carácter de las mismas. Lo que está claro es que la misión desarrollada en la guerra de los Balcanes es la más valorada por los docentes entrevistados en este estudio.

E: Claro, hombre, en el caso de Bosnia, creo que fue realmente una misión humanitaria y de paz muy potente y con una buena repercusión a nivel de imagen social...

P: Sí, exactamente....además, eso sí lo vio la gente y se catalogó como misión de paz. Pero el problema es que se llamen misiones de paz a misiones que realmente no lo son, o yo no creo que sean...., a lo mejor, comenzaron siendo de paz pero después no lo terminaron siendo... Esto perjudica muchísimo a las FAES, y esa imagen social es negativa... y lo veo dificil trasladar este tipo de cuestiones a la escuela...

En efecto, como plantea el docente anteriormente citado, el problema es que se denominen misiones de paz a misiones que realmente no lo son tanto, lo cual perjudica a las Fuerzas Armadas y genera una imagen social negativa de esta institución en el contexto escolar. En todo caso, al margen de ello, muchos docentes se cuestionan también cómo poder trabajar la educación para la paz en base a esas misiones humanitarias y de paz cuando tienen una imagen de las Fuerzas Armadas muy vinculada a la guerra y no a la paz. En este punto, todos los docentes sin ningún tipo de excepción consideran que es muy complicado vincular educación para la paz y Fuerzas Armadas.

E: Es decir, que para ti, el problema estaría en esa imagen social negativa que no permite esa traslación o por lo menos intento de trabajar en la escuela las misiones de paz, las misiones humanitarias como algo que tiene valor pedagógico...

P: Exactamente...sí, hacia la escuela, lo veo complicado.... 
La propia imagen social de las misiones de paz determina o puede condicionar la imagen que tienen los docentes sobre las Fuerzas Armadas, y es que esto también tiene que ver con la gestión de la imagen de las Fuerzas Armadas por parte de los medios de comunicación, pero también por parte de los políticos que no son especialmente clarificadores cuando se trata de valorar el carácter político o incluso moral de las actuaciones que realizan las Fuerzas Armadas en el exterior.

E: Es decir, que planteas que las misiones humanitarias y de paz a lo mejor no son de paz, no son cómo parecen que son o nos hacen creer los políticos ino?

P: Sí, yo creo que hay mucha confusión con este tipo de informaciones que sale en la televisión y en los medios...y es que si te dicen que las fuerzas armadas hacen tareas humanitarias sí te lo crees, pero cuando hablan de misiones de paz y están ofreciendo imágenes de guerra, es poco creíble hablar de paz.

E: Ajá....por tanto, te cuesta identificar esas misiones de paz como auténticas misiones de paz. $P$ : Sí, es una cuestión de imagen pero también de los políticos, de la manera que tienen los políticos de vendernos las cosas de tal manera que parece que se creen que los españoles vivimos en otro mundo ino?...Las misiones de paz están bien cuando realmente son de paz, es decir, se va a los países a reconstruir cosas, puentes, carreteras, o ayudar a hacer hospitales y cosas humanitarias, pero creo que hay misiones de paz que realmente no lo son....Por ejemplo, Afganistán no es lo mismo que cuando fue lo de Bosnia,....no sé.

Esas limitaciones o condicionantes que consideran los docentes que existen para trabajar la escuela ese tipo de conocimientos vinculados a las misiones humanitarias y de paz, también se acentúan cuando se piensa en el pasado o en la tradición militarista en España. Ciertamente, los docentes entrevistados aluden a que existe un sesgo sobre lo militar en España vinculado con la necesidad de que nuestro país no parezca violento o que resulte militarista. En este punto, un docente considera que las Fuerzas Armadas son una institución invisible para la ciudadanía y eso es algo intencional, es decir, que no parece democrático ni progresista ni moderno la visibilización de las Fuerzas Armadas en una sociedad como la nuestra, lo cual resulta paradójico porque vivimos en una democracia hace muchos años y el papel de las Fuerzas Armadas es precisamente defender el orden constitucional y, por ende, la democracia y la seguridad humana.

E: Hay un sesgo...

P: Sí, se le ha tapado para que no parezca que España es un país militarista, o que tenemos un país violento y tal... cosa que a mí no parece correcto. Una parte fundamental de la sociedad es que...no ha conocido.

E: Has comentado con los chicos de tu clase o en tu colegio... isaben que este mes es el día de las Fuerzas Armadas en Málaga?

$P$ : Ellos no lo saben. No están informados de este tema... 
Una clave fundamental en nuestro estudio es la comprensión de los factores condicionantes o dificultades que existen en los centros educativos para promover en ellos una imagen pacífica de las Fuerzas Armadas. En este sentido, la falta de conocimientos sobre las misiones de paz de las Fuerzas Armadas es la razón aludida por la mayoría de docentes como el principal problema para promover esa imagen pacífica en la escuela, en concreto, un 53,6\% plantea esta opción mayoritaria. Ciertamente, esta resulta chocante en una sociedad de la información donde los medios de comunicación nos ofrecen permanente información actualizada sobre todo tipo de temas, y también sobre las misiones humanitarias y de paz de las Fuerzas Armadas Españolas. No obstante, podemos interpretar este dato como una nítida falta de visibilización social y en los medios de comunicación, de las funciones, tareas e iniciativas de las Fuerzas Armadas. En cierta forma, el papel de los medios de comunicación y la opinión pública han determinado históricamente determinadas intervenciones militares y de pacificación, como por ejemplo, las intervenciones llevadas a cabo en los conflictos de Bosnia y Kosovo, donde la participación de las Fuerzas Armadas Españolas ha sido relevante. Dicho esto, pensamos que la opinión pública distingue perfectamente entre las intervenciones por interés nacional o estratégico y las intervenciones por razones humanitarias y de mantenimiento de la paz. Estas últimas encuentran un mayor reconocimiento y apoyo social que las primeras, es más, probablemente los medios de comunicación, preocupados últimamente por el lado más humano de los conflictos bélicos, están contribuyendo a modificar las actitudes de los ciudadanos en función del papel y los intereses estratégicos de nuestro país y de los países aliados, y las repercusiones que puede tener para la propia seguridad y libertades todo tipo de iniciativas e intervenciones militares, con independencia de su naturaleza.

Asimismo, resulta muy importante destacar que un $23,2 \%$ del profesorado manifieste que la falta de apertura por parte de las Fuerzas Armadas para el conocimiento y comprensión de sus acciones es un hándicap significativo para la promoción activa y reflexiva de las mismas en los centros escolares. Esto lo podemos interpretar como una crítica constructiva a una mirada sociopolítica que no comparte la potencialidad pedagógica de las manifestaciones o actuaciones públicas de las Fuerzas Armadas, sean de la naturaleza que sean. Asimismo, lo podemos entender como una forma de invisibilizar un patriotismo no bien visto por determinados sectores de la política y de la sociedad que todavía vincula exaltación nacionalista de corte conservadora con los protocolos y manifestaciones públicas de las Fuerzas Armadas en el contexto social más cercano. Además, es bien sabido que, aunque las ordenanzas obliguen a la sencillez y austeridad en la realización de los protocolos militares, históricamente todos los ejércitos nacionales han dedicado mucho tiempo y esfuerzos humanos y materiales a 
cumplir tareas rutinarias de exaltación acrítica de la nación a través de diversos tipos de protocolos y ceremonias, desde una gran variedad de paradas y desfiles conmemorativos, juras de bandera, revista de tropas, entrega de despachos y medallas, fiestas religiosas castrenses, y rendición de honores a autoridades civiles o militares y a instituciones o símbolos representativos del Estado. Así pues, no creemos que invisibilizar la imagen social de las Fuerzas Armadas sea algo positivo para la sociedad y la escuela, más bien al contrario, es necesario que, al igual que otras instituciones sociales, se modernicen y actualicen sus intervenciones haciéndolas más inclusivas y abiertas al escrutinio público, la cooperación y la participación de la ciudadanía. Precisamente, el día de las Fuerzas Armadas así como las campañas informativas son una buena muestra de la potencialidad social y educativa de las Fuerzas Armadas para contribuir activamente a la generación de una conciencia social de valores de paz, democracia, seguridad humana, igualdad y libertad. No obstante, este tipo de iniciativas son muy específicas en el espacio y en el tiempo, y resulta imprescindible una mayor visibilización, aprovechando todo el potencial de las TIC, de las redes sociales y también con propuestas activas de difundir una imagen pacífica en la juventud y en la ciudadanía de nuestro país.

Además, un factor importante lo podemos encontrar en la propia juventud, muy interesada por los vínculos de respeto al medio ambiente, la promoción del deporte y la actividad física, así como el ejemplo moral de la imagen de modernidad que supone la incorporación en igualdad de oportunidades de mujeres en las Fuerzas Armadas. Esto lo podemos confirmar en nuestro estudio, y es que sólo un 16,1\% del profesorado considera que existe un escaso interés del alumnado de educación primaria sobre la promoción pacífica y la posibilidad del conocimiento de las Fuerzas Armadas en los centros educativos. Finalmente, un 7,1\% subraya que existen pocos apoyos por parte de la administración educativa para promover y vincular la imagen pacífica de las Fuerzas Armadas en las escuelas. Esto es algo que podemos observar, o mejor dicho, no observar en la normativa educativa vigente, y es que, por ejemplo, en el caso concreto de la Comunidad Autónoma de Andalucía, no aparece ninguna mención que de cobertura curricular al conocimiento de las funciones de las Fuerzas Armadas (véase la Orden de 10 de agosto de 2007, por la que se desarrolla el currículo correspondiente a la Educación Primaria en Andalucía). En todo caso, sí es cierto que diversas editoriales en sus propuestas pedagógicas sí incorporan el conocimiento de profesiones ligadas a la seguridad y el bienestar ciudadano como el caso de policía, bombero, etc.., pero se obvia, consciente o inconscientemente, la posibilidad de incluir la profesión militar como una profesión más de la vida social. Esto es síntoma más de la escasa presencia pública de las Fuerzas Armadas en la vida social y escolar, lo cual para el profesorado encuestado, es responsabilidad, sobre todo, de las propias Fuerzas Armadas. No 
obstante, la problemática es compleja y no depende exclusivamente de las iniciativas o de la propia voluntad de las Fuerzas Armadas en mejorar su imagen social en la escuela, y de promover el conocimiento y comprensión de sus misiones humanitarias.

También es una cuestión de política general, y de política educativa, porque la incorporación expresa de las Fuerzas Armadas en el curriculum escolar no existe. Ahora bien, la educación para la paz es un contenido transversal dentro del contexto educativo, y, de manera más específica, un elemento clave dentro del curriculum de la asignatura de "Educación para la Ciudadanía" que se imparte como asignatura en $5^{\circ}$ curso de primaria. Asimismo, no podemos olvidar que nuestro actual sistema educativo tiene una especial preocupación por el aprendizaje por competencias básicas, y en concreto, comprender y estudiar las misiones humanitarias y de paz de las Fuerzas Armadas podría englobarse en el marco de la competencia social y ciudadana, entendida como aquélla que permite vivir en sociedad, comprender la realidad social del mundo en que se vive y ejercer la ciudadanía democrática, tal y como viene recogido en Real Decreto $1513 / 2006$, de 7 de diciembre, por el que se establecen las enseñanzas mínimas de la educación primaria, así como en el Decreto 230/2007, de 3 I de julio, por el que se establece la ordenación y las enseñanzas correspondientes a la educación primaria en Andalucía. En este sentido, esta opción depende más de los planteamientos pedagógicos de la comunidad educativa y de los docentes que de la propia ordenación curricular expresa en la normativa, puesto que es lo suficiente flexible y apuesta decididamente por la autonomía educativa de centros y docentes.

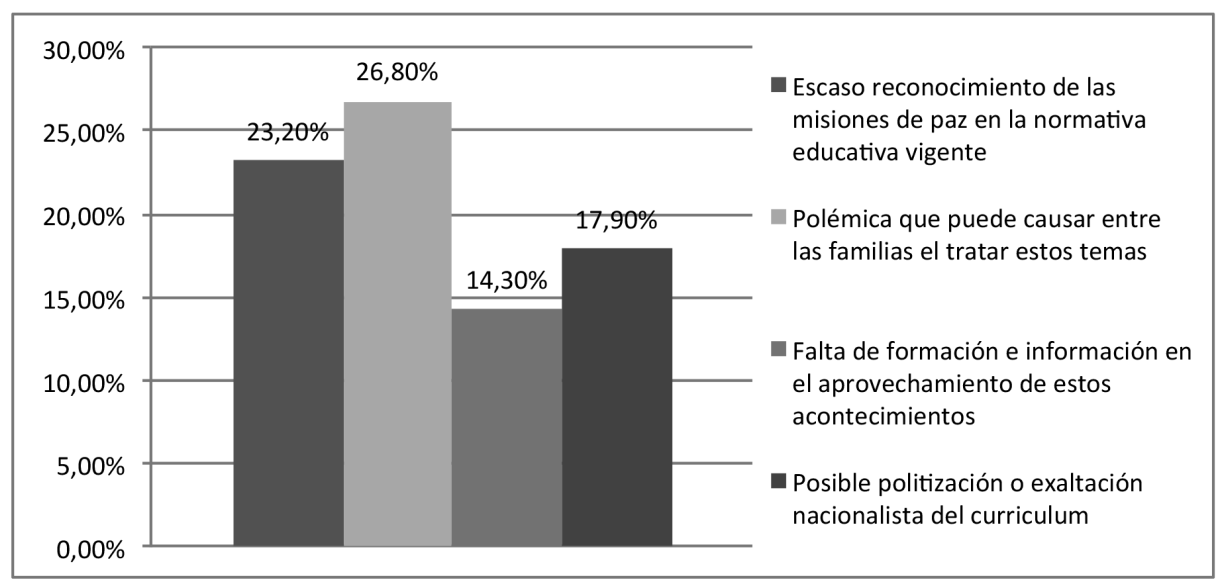

Gráfico I. ¿Cuál es el problema más importante que puede acontecer para la promoción de la imagen pacífica de las fuerzas armadas en los centros educativos? 
Resulta muy interesante que, cuando se le preguntaba directamente al profesorado sobre las causas que pueden limitar la posible integración curricular de hechos o situaciones relacionadas con las misiones humanitarias y de paz de las Fuerzas Armadas, el desconocimiento de las mismas no sea el elemento mayoritario en sus respuestas. Más bien al contrario, un porcentaje significativo de docentes $(26,8 \%)$ considera que la limitación mayor puede estar en la posible polémica que puede causar entre las familias el tratar estos temas sobre los militares y la paz en el mundo, mientras que el resto de opciones son minoritarias. De hecho, un $23,2 \%$ del profesorado plantea que la clave puede estar en el escaso reconocimiento de las misiones de paz en la normativa educativa vigente. De todos modos, como hemos indicado anteriormente, si bien es cierto que no hay mención expresa en el curriculum de educación primaria sobre las misiones de paz de las Fuerzas Armadas, los docentes son conscientes de la flexibilidad y potencialidad del actual marco normativo que promueve el aprendizaje por competencias, y consideramos que la competencia social y ciudadana puede incluir este tipo de iniciativas ligadas a la promoción de la educación para la paz en la escuela.

Por su parte, y en tercer lugar, encontramos una respuesta que consideramos de gran importancia en el análisis pedagógico crítico que venimos haciendo en este estudio. Ciertamente, y a pesar de que la muestra del profesorado encuestado es más bien joven, persiste la idea de que tratar estos temas vinculados a las Fuerzas Armadas implica una posible politización o exaltación nacionalista del curriculum escolar (17,9\%). En efecto, ningún pedagogo o docente puede defender postulados nacionalistas o de ideologías extremas, pero es algo obvio que nadie puede prohibir en la escuela de hoy el ejercicio de la valoración respetuosa de los valores constitucionales, y entre ellos, está el conocimiento y reconocimiento de aspectos polémicos pero que son aceptados mayoritariamente por toda la ciudadanía. Por ejemplo, la monarquía constitucional es una realidad clara y nítida en el conocimiento de la estructura y funcionamiento político de nuestro país, pero es obvio que puede existir $y$, además es sano, que haya críticas sobre la misma pero siempre desde el respeto a la legitimidad constitucional que da el derecho clave a la libertad de expresión y de opinión. Pues bien, no podemos negar la oportunidad de que los más jóvenes valoren positivamente la identidad cívica y los valores de libertad, igualdad y democracia configurados también en un sentimiento de pertenencia y de patriotismo democrático, liberado de ataduras ideológicas extremas, y consciente de que valorar lo propio implica ser crítico y respetuoso también con las ideas, las imágenes, los símbolos y las manifestaciones propias y distintas. 
Con un $14,3 \%$ de los docentes, nos encontramos con la opción de la falta de formación e información en el aprovechamiento didáctico de los acontecimientos referidos a las misiones humanitarias y de paz. En verdad, como hemos manifestado con anterioridad, son escasas las oportunidades de visibilización de las Fuerzas Armadas en el ámbito social, y por tanto, es lógico en cierta medida que esta opción también tenga un peso significativo entre los docentes puesto que las noticias relacionadas con las Fuerzas Armadas en los medios de comunicación es generalmente relacionadas con aspectos más bien negativos de la realidad militar, sobre todo en los trágicos casos de fallecimientos de militares en misiones políticamente calificadas como de paz, pero socialmente cuestionadas en su origen y naturaleza. Esta circunstancia es muy importante para los docentes, y es que distinguir correctamente entre misiones humanitarias y de paz no resulta del todo fácil. El caso más claro de esta difícil separación lo podemos encontrar en la misión que realizan las Fuerzas Armadas Españolas en Afganistán. Incluso los propios políticos no se ponen de acuerdo en calificar el carácter belicista o pacifista de esta misión, sólo tenemos que leer los periódicos o el propio diario de sesiones del parlamento español cuando el gobierno español solicitó la autorización de esta misión. También, un 12,5\% del profesorado considera como grave limitación para la integración curricular de estos temas el propio desconocimiento de las misiones humanitarias y de paz, mientras que un $5,4 \%$ responsabiliza directamente a las Fuerzas Armadas por la escasa capacidad de difusión y apoyo en su posible contribución en los contextos escolares. No obstante, también hay que señalar que no podemos achacar a las Fuerzas Armadas su falta de voluntad de acercamiento al ámbito escolar.

Aunque existe una mayor receptividad entre el profesorado más joven de los claustros docentes, todavía persiste un significativo recelo hacia todo lo militar en los centros educativos, sea por prejuicios ideológicos o por un cuestionamiento histórico-conceptual. De hecho, cuando en los centros planteábamos este estudio de investigación nos encontrábamos el rechazo frontal de muchos docentes porque pensaba que era un estudio intencionalmente manipulado por parte del Ministerio de Defensa para promover cierto sentimiento nacionalista. Lógicamente, esto es absolutamente falso, y aunque fue explicado por el equipo investigador, la verdad es que el rechazo hacia este estudio tenía que ver con el miedo a que estuviera en la línea de promover o fomentar algún tipo de identidad nacionalista en vez de estimular el estudio sobre la educación para la paz. 


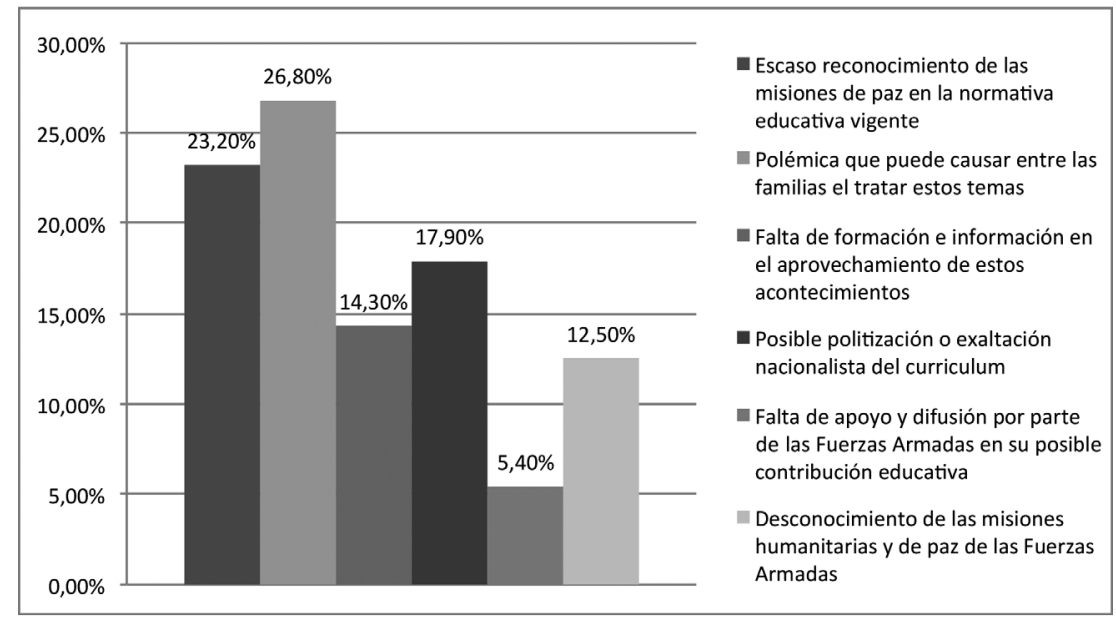

Gráfico 2. De las siguientes consideraciones que pueden dificultar la integración curricular de hechos o situaciones relacionadas con las misiones humanitarias y de paz de las fuerzas armadas, ¿cuál es, a su juicio, la más importante?

E: Como una exaltación nacionalista o....

P: Yo creo que sí, que tratar este tema es difícil, en esa línea, como si fuera que queremos fomentar una exaltación nacionalista...

E: ¿Y cómo salió este tema en el claustro...?

P: Bueno, salió varias veces, tanto por el tema del cuestionario, de la participación docente en el cuestionario, como por la propia participación de los niños en el concurso..., con el tema de los dibujos. Salió el comentario de que el proyecto era de tal tema, la idea era tal...pero la idea que salió es que el proyecto de investigación era para exaltar el nacionalismo español en la escuela, no sé, como que en las palabras de mis compañeros se veía eso, ¿no? El miedo a que sea una cosa política, y no quieren entrar por esta razón.

\section{Conclusiones finales}

La inclusión en la educación para la paz de iniciativas y acciones escolares vinculadas al estudio, comprensión y valoración de las misiones humanitarias y de paz de las Fuerzas Armadas modula entre la indiferencia y la invisibilización desde el punto de vista del análisis pedagógico del pensamiento docente. En este estudio, hemos descubierto que el profesorado concibe que, en muchos casos, es muy complejo e incluso contradictorio, el promover una educación en valores y de paz tratando o haciendo incluso alusión a las misiones humanitarias y de paz de las Fuerzas Armadas, no tanto por el carácter, orientación y sentido moral y ético 
de estas acciones humanitarias, sino por los prejuicios y estereotipos existentes respecto a los valores e identidad de las Fuerzas Armadas de nuestro país.

También, no podemos negar que muchos docentes se cuestionan el hecho de si las acciones denominadas humanitarias y de paz, no son sino una forma velada y eufemística de calificar operaciones de imposición cultural o ideológica, o sencillamente operaciones militares que tienen más de guerra que de paz, y, por tanto, las críticas sobre las propias misiones de paz hacen pensar a muchos docentes que no es pertinente la inclusión de estos temas en el curriculum escolar (Leiva, 20I2). Igualmente, es posible que el profesorado esté impregnado e imbuido de toda una concepción pedagógica e idealista de educación para la paz donde es necesario evitarle al niño tratar temas vinculados a la guerra, la violencia y la seguridad. Es cierto que muchos centros escolares promueven en sus planes de convivencia todo un conjunto de medidas e iniciativas de educación para la paz que van desde la mediación, los contratos pedagógicos, la gestión de los conflictos escolares, la tutoría de iguales, la orientación y la acción tutorial (Binaburo y Muñoz, 2007). Ahora bien, dentro de los contenidos curriculares que pueden impartirse en áreas tales como Ciencias Sociales y Educación Cívica, no sólo es posible sino deseable el promover el estudio crítico y reflexivo de este tipo de situaciones sociales y políticas, muy alejadas a lo mejor de los más jóvenes, pero indispensables para promover en los centros educativos de una conciencia e identidad cívica donde se reconozca el papel de las Fuerzas Armadas como un instrumento que todos los niños y niñas deben conocer, al igual que conocen otras instancias o profesiones.

De la misma manera, el valor de la igualdad de género puede ser un ejemplo importante para los alumnos de educación primaria, y es que, tal y como apuntan Gómez y Sepúlveda (2009, 198), todos los países “coinciden en valorar muy positivamente la participación de mujeres militares en misiones internacionales de paz, en particular, la ventaja del intercambio cultural con otras mujeres y con niños, sobre todo de países islámicos". Este tipo de consideraciones también aluden a la potencialidad de poder trabajar en las aulas diferentes competencias educativas a través del aprendizaje y estudio de las misiones humanitarias y de paz de las Fuerzas Armadas, ya que su análisis supone conocer aspectos geográficos, de conocimiento del medio; lingüísticos, sociales y ciudadanos, e interculturales. Además, según Rodríguez (2010, p.7) el que "unas fuerzas armadas encajen en su sociedad matriz depende en gran medida de cómo sean utilizadas, de su conducción estratégica. Por muy bien organizadas, equipadas y preparadas que estén, y por mucho que gocen del apoyo de sus ciudadanos, un empleo incorrecto puede hacerles perder la necesaria identificación con esa sociedad, su apoyo, pero también distraerlas de su verdadero objetivo o hacer que desempeñen sus cometidos de manera ineficaz". 
En nuestro estudio sobresale una idea de gran relevancia y es que resulta necesario en una sociedad moderna como la española un cambio de mirada estratégica de las propias Fuerzas Armadas, donde lo educativo, lo moral y lo ético impregnen sus nuevas relaciones e interacciones institucionales, y en el caso concreto de la escuela, se hace imprescindible promover programas de sensibilización así como seminarios y encuentros donde el diálogo, la crítica respetuosa y constructiva, el contraste de pareceres y la interculturalidad sean un punto de partida para mejorar su imagen social en la escuela (Mayor, 2002; Santos, 2009). El marco normativo puede impulsar esta orientación en el marco de diferentes áreas curriculares y también desde la perspectiva de la transversalidad democrática como reflejo de los valores de pluralismo, respeto y libertad consagrados en nuestro marco constitucional. Desde luego resulta importante señalar que las Fuerzas Armadas deberían llegar a acuerdos de conocimiento y colaboración con las autoridades político-educativas.

En definitiva, si bien no podemos obviar que, por el momento, y desde el punto de vista de los docentes, existe reticencias acerca de la incorporación curricular y tratamiento didáctico de la promoción de las misiones humanitarias y de paz en sus aulas, hemos de admitir la emergente necesidad de que la escuela asuma sin complejos ni tapujos la potencialidad pedagógica de estos conocimientos e imágenes socioculturales de la realidad humana para educar reflexiva y críticamente en valores como la seguridad humana, la cultura de defensa democrática, la solidaridad y la paz.

\section{Referencias}

Adalede (2007). Educación para la ciudadanía: la Defensa, compromiso cívico y solidario al servicio de la Paz. Madrid: Ministerio de Defensa.

Ajangiz, R. (2003). Intervenciones humanitarias y opinión pública: de la exigencia al desencanto, Revista CIDOB d'Afers Internacionals, 60, 23-42

Binaburo J. A. y Muñoz, B. (2007). Educar desde el conflicto. Guía para la mediación escolar. Barcelona: CEAC.

Casas, F. J., De la Esperanza, J. M. y Martín-Pinillos, J. M. (2007). Educación para la Ciudadanía: la defensa, compromiso cívico y solidario al servicio de la paz. Madrid: Ministerio de Defensa, Secretaría General Técnica.

Dandeker, C. y Gow, J. (1997). The Future of Peace Support Operations: Strategic Peacekeeping and Success. Armed Forces and Society, 23 (3), 327-347. 
Díez, J. (1999). Identidad nacional y cultura de defensa. Madrid: Síntesis.

Galtung, J. (2003). Paz por medios pacíficos: paz y conflicto, desarrollo y civilización. Bilbao: Bakeaz.

García, A. (2008). ilntervención versus asistencia? Las misiones asignadas a las Fuerzas Armadas Españolas: ser visibles. Murcia: Universidad de Murcia.

Gómez, M. y Sepúlveda, I. (2009). Las mujeres militares en España (I988-2008). Madrid: Instituto Universitario General Gutiérrez Mellado-UNED.

Jares, X. R. (1999). Educación para la paz. Su teoría y su práctica. Madrid: Popular.

Leiva, J. (20/2). Educación para la paz y seguridad humana en una sociedad intercultural. Barcelona: Octaedro.

Martín, J.y Olianas, E. (2006). La juventud universitaria española ante la defensa nacional: encuesta sobre su percepción y actitudes. Madrid: Grupo Complutense de Investigación sobre Neuropsicopedagogía de la Agresión-IEB y Universidad Complutense de Madrid.

Mayor, F. (2002). Ciudadanía democrática. Reinventar la democracia, la cultura de paz, la formación cívica y el pluralismo. En Imbernón, F. (Coord.), Cinco ciudadanías para una nueva educación (I5-27). Barcelona: Graó.

Muñoz, F. y Molina, B. (2004). Manual de paz y conflictos. Granada: Universidad de Granada.

Ospina, J. (2010). La educación para la paz como propuesta ético-política de emancipación democrática. Origen, fundamentos y contenidos. Universitas. Revista de Filosofía, Derecho y Política, II, 93-I 25.

Rodríguez, J. (2010) Reflexiones sobre el presente y futuro de las Fuerzas Armadas, Boletín de Información CESEDEN-Ministerio de Defensa, 316, 4-19.

Ruiz, J. (1996) Metodología de investigación cualitativa. Bilbao: Deusto.

Santos, M. A. (2009). Migraciones, sostenibilidad y educación. Revista de Educación, número extraordinario, 123-145

Stake, R. E. (1998). Investigación con estudio de casos. Madrid: Morata

Tuvilla, J. (1998). Educación en Derechos Humanos, hacia una perspectiva global. Bilbao: Desclée De Brouwer.

Tuvilla, J. (2004). Cultura de paz: fundamentos y claves educativas. Bilbao: Desclée De Brouwer. 